\title{
Analisis Video Comments to Video Views Ratio Instagram Pada 5 Brand Laptop Di Indonesia
}

\author{
Bonefansius lando kako \\ landokako98@gmail.com
}

\begin{abstract}
Teenagers all over the world are so attached to social media, they continue to communicate through social media. The problem that occurs in social media instagram is the existence of teenagers who upload their photos. Most of them tend to upload photos that show the luxury and behavior of pride, this can disrupt the social relationships of teenagers. Existence can we know also with one word that is existence. Where the existence of the intent is with the response of people around us this proves that our existence is recognized. In this article I will discuss about the existence of adolescent instagram users. In this discussion the author will describe the results of research on the phenomenon of social media instagram in social existence in adolescents in Jakarta. The fact that happens among teenagers in Jakarta that teenagers really need self-existence but should be done well and wisely not excessively. Keywords: social media, social existence, perspective
\end{abstract}

\begin{abstract}
ABSTRAK
Remaja di seluruh dunia begitu lekat dengan media sosial, mereka terus berkomunikasi lewat media sosial. Masalah yang terjadi di media sosial instagram adalah eksistensi remaja yang mengupload foto-foto mereka. Kebanyakan mereka cenderung mengupload foto yang menunjukan kemewahan dan perilaku kesombongan, hal ini dapat menggangu hubungan sosial para remaja. Eksistensi bisa kita kenal juga dengan satu kata yaitu keberadaan. dimana keberadaan yang di maksud adalah dengan adanya respon dari orang di sekeliling kita ini membuktikan bahwa keberadaan kita diakui. Dalam tulisan ini saya akan membahas mengenai eksistensi remaja pengguna instagram. Pada pembahasan ini penulis akan menguraikan hasil penelitian mengenai fenomena media sosial instagram dalam eksistensi sosial pada remaja di Jakarta. Kenyataan yang terjadi di kalangan remaja Jakarta bahwa remaja memang sangat memerlukan eksistensi diri tetapi harus dilakukan secara baik dan bijaksana tidak secara berlebihan
\end{abstract}

Keyword : Credibility Account instagram ; Social Media Marketing ; Social Mediainstragram ; Video Comments to Video Views Ratio ; 5 brand laptop di indonesia

\section{PENDAHULUAN}

Kemajuan teknologi telah mengantarkan manusia untuk menciptakan bentuk baru dalam berinteraksi dan bersosialisasi, salah satunya adalah inovasi teknologi komunikasi berupa media sosial. Sebagai sarana komunikasi yang efektif, media sosial sangat berperan dalam aktifitas keseharian bersosial di masyarakat. Memilih gaya hidup hedonis sesungguhnya tidak akan pernah membawa kebahagiaan dan kepuasaan dalam hidup. Teknologi komunikasi sangat penting dalam masyarakat informasi, karena dengan teknologi ini memudahkan orang untuk 
bertukar informasi dengan orang lain melalui sistem komunikasi yang berbasis komputer. Sistem komunikasi tersebut ada yang menamakan sebagai teknologi komunikasi baru, media baru, atau komunikasi interaktif. Media baru cenderung dihubungkan dengan internet, karena internet dianggap meliputi banyak hal yang tidak bisa dilakukan oleh media cetak dan elektronik. Instagram adalah sebuah aplikasi berbagi foto yang memungkinkan pengguna mengambil foto, menerapkan filter digital, dan membagikannya ke berbagai layanan jejaring sosial, termasuk milik Instagram sendiri.Instagram berdiri pada tahun 2010 dan didirikan oleh dua bersahabat Kevin Systrom dan Mike Krieger.(Mahendra, 2017) Kehadiran media sosial instragram dapat membangun sebuah brand, instragram Adapun Top 5 Vendor laptop di Indonesia, diantaranya yaitu : DELL ,HP,APPLE ASUS LENOVO (“Top 5 Vendor Laptop Di Indonesia). Penelitian ini menggunakan metode eksploratif kuantitatif, dan akan menghitung menggunakan rasio-rasio yang ada pada instragram . Pada penelitian (Permana and Meinarni 2021) menjelaskan bahwa terdapat 17 rasio yang ada pada sosial media instragram dan relevan digunakan sebagai media ukur kredibilitas akun yang ada. Penelitian ini hanya berfokus untuk menghitung kredibilitas Video Comments to Video Views Ratio pada Top 5 Vendor laptop di Indonesia. Adapun Top 5 Vendor laptop di Indonesia, diantaranya yaitu : DELL ,HP,APPLE ASUS LENOVO ("Top 5 Vendor laptop .). Tujuan dari penelitian ini adalah mengetahui kredibilitas performa dari akun instragram Top 5 Vendor Laptop menggunakan Video Comments to Video Views Rasio.

\section{TINJAUAN PUSTAKA}

Komunikasi Massa Dan New Media. Proses Komunikasi Pada Hakikatnya Adalah Proses Penyampaian Pikiran Atau Perasaan. Pikiran Bisa Berupa Gagasan, Informasi, Opini, Dan Lainnya.Sedangkan Perasaan Dapat Berupa Keyakinan, Kepastian, Keberanian, Dan Sebagainya Yang Timbul Dari Lubuk Hati Seseorang. Pada Era Modern Seperti Sekarang Komunikasi Massa Yang Paling Popular Adalah Komunikasi Massa Melalui Media Internet Atau Yang Sering Kita Sebut Dengan Online Media. Dalam Komunikasi Massa, Menurut Cangara

(2007) Selalu Melibatkan Peran Media Atau Alat Atau Sarana Yang Digunakan Untuk Menyampaikan Pesan

Dari Komunikator Kepada Khalayak. Pengertian Media Massa Sendiri Adalah Alat Yang Digunakan Untuk Menyampaikan Pesan Dari Sumber Ke Khalayak (Penerima) Dengan Menggunakan Alat-Alat Komunikasi Mekanis, Seperti Surat Kabar, Film, Radio, Dan Televisi. Dari Penjelasan Tersebut Dapat Disimpulkan Bahwa

Media Massa Merupakan Media Yang Digunakan Dalam Penyampaian Pesan Dari Komunikator Kepada Khalayak Yang Berjumlah Besar Secara Serempak. Media Massa Sangat Berperan Dalam Perkembangan Atau Bahkan Perubahan Pola Tingkah Laku Dari Suatu Masyarakat, Oleh Karena Itu Kedudukan Media Massa Dalam Masyarakat Sangatlah Penting. Dengan Adanya Media Massa, Masyarakat Yang Tadinya Dapat Dikatakan Tidak Beradab Dapat Menjadi Masyarakat Yang Beradab. Hal Itu Disebabkan, Oleh Karena Media

Massa Mempunyai Jaringan Yang Luas Dan Bersifat Massal Sehingga Masyarakat Yang Membaca Tidak Hanya Orang-Perorang Tapi Sudah Mencakup Jumlah Puluhan, Ratusan, Bahkan Ribuan Pembaca 
Instragram Merupakan Bagian Dari New Media Yang Memiliki Perkembangan Terpesat Dibandingkan

Dengan Kategori New Media Yang Lainnya Seperti Facebook,Tiktok, Youtube, Dan. Dari Sekian Banyak Aplikasi Sosial Media, Isnstragram Menjadi Aplikasi Yang Memiliki Pengguna Aktif Terbanyak. Intragram

Merupakan Jejaring Sosial Media Dalam Bentuk Foto Dan Video Yang Umumnya Berdurasi 15 Detik. Pada Aplikasi Instragram Pengguna Dapat Membuat Foto Dan Video Dengan FilterFilter Yang Spesial Serta

Menggunakan Lagu Yang Sedang Trending. Selain Itu, Pengguna Dapat Membagikan Video Yang Dibuat Ke

Aplikasi Lain Seperti Tiktok Atauoun Twitter. Di Indonesia, Fenomena Anak Muda Dalam Menggunakan

Instragram Menunjukan Antusiasme Yang Sangat Massif. Meraka Berlomba Membangun Identitas Demi Mendapatkan Citra Yang Diinginkan, Seperti Dipuji Dan Dikenal Oleh Banyak OrangKredibilitas Akun Instragram Merupakan Suatu Hal Yang Cukup Penting Untuk Berbagai Kepentingan. Kredibilitas Sebuah Akun Instragram Dapat Diukur Dari Tingkat Performa Yang Dihasilkan Secara Matematis. Dalam Mengukur Performa Diperlukan Skala Pengukuran Yang Tertuang Ke Dalam Rasioukuran yang tertuang ke dalam rasio.

\section{METODE PENELITIAN}

Identifikasi Variabel Penelitian Variabel penelitian menurut Kerlinger adalah konstuk (constructs) atau sifat yang akan dipelajari, dan suatu sifat tersebut bisa diambil dari nilai yang berbeda, artinya variable adalah suatu yang bervariasi dan memiliki nilai. Jadi variabel penelitian adalah sesuatu yang dipelajari oleh peneliti berupa obyek atau kegiatan berbentuk apa saja yang memiliki sifat, nilai serta bervariasi sesuai dengan kategori yang ditetapkannya kemudian ditarik kesimpulan. Variabel penelitian memiliki berbagai macam, namun dalam penelitian ini penulis hanya memafarkan dua variabel sesuai dengan tujuan penelitian yang telah diuraikan pada $\mathrm{BAB} 1$ dan berdasarkan teori yang diuraikan dalam BAB II, maka dapat diidentifikasi variabel penelitian sebagai berikut:

1. Variabel bebas (Independent Variabel) Variabel bebas merupakan variabel pokok atau inti yang menyebabkan timbul dan berubahnya suatu objek, artinya variabel bebas Sugiono, Metode Penelitian Kuantitatif Kualitatif Dan R\&D, (Bandung: Alfabeta. 2015). merupakan variabel yang mempengaruhi. Adapun yang menjadi variable bebas dalam penelitian ini adalah media sosial instagram

2. Variabel terikat Variabel terikat merupakan variabel yang dipengaruhi atau hasil yang ditimbulkan dari variable bebas. Adapun yang menajadi variabel terikat dalam penelitian ini adalah perilaku keagamaan remaja 


\section{HASIL DAN PEMBAHASAN}

Akun Akun Instragram Top 5 Vendor Laptop Di Indonesia 2021, Diantaranya :

1. DELL

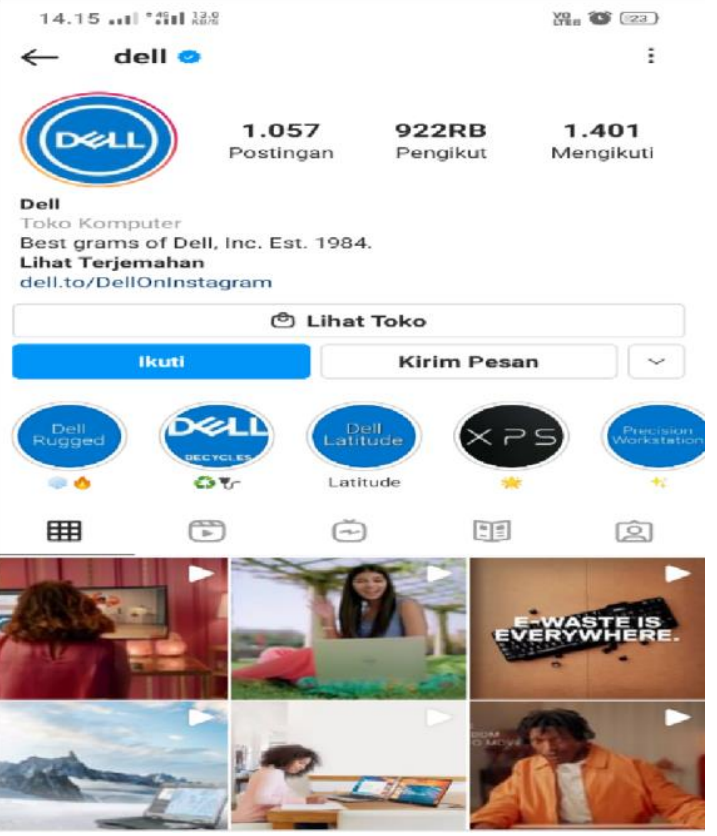

Gambar 1. Akun Instragram Dell

2. Hр

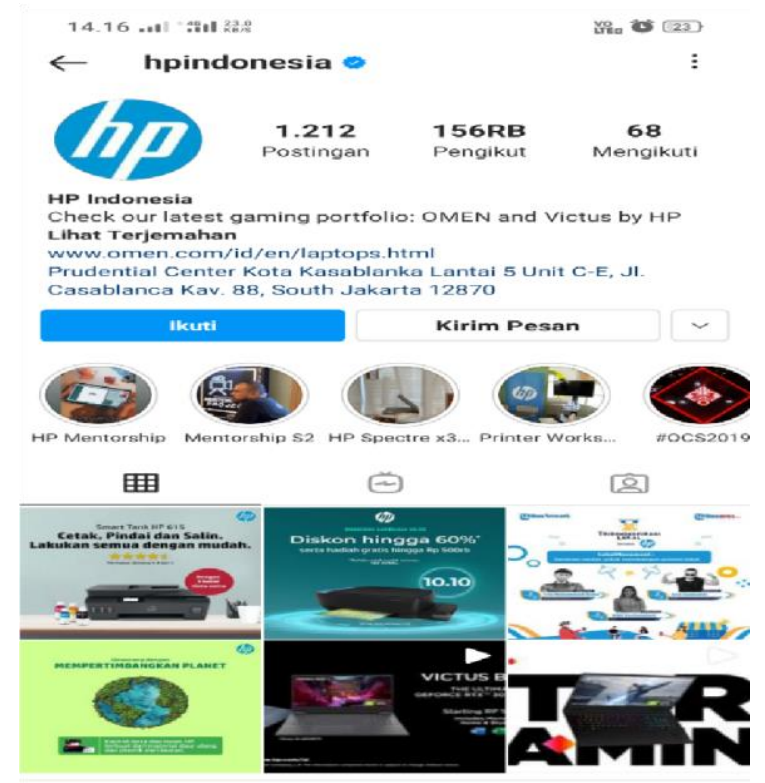

Gambar 2. Akun Akun Instragram Hp 
3. APPLE

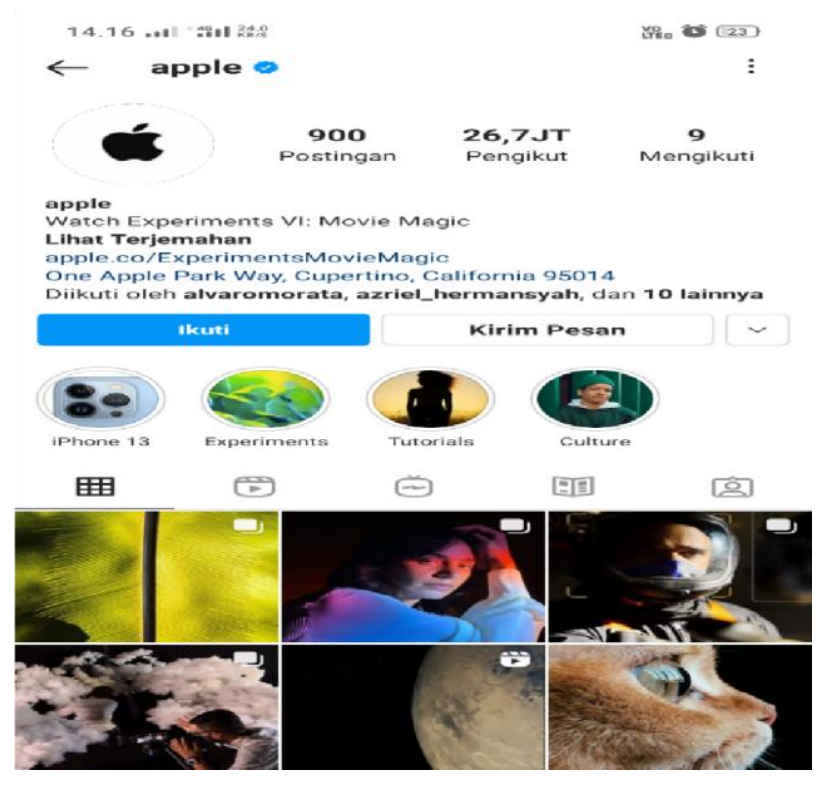

Gambar 3. Akun Akun Instragram APPLE

\section{ASUS}

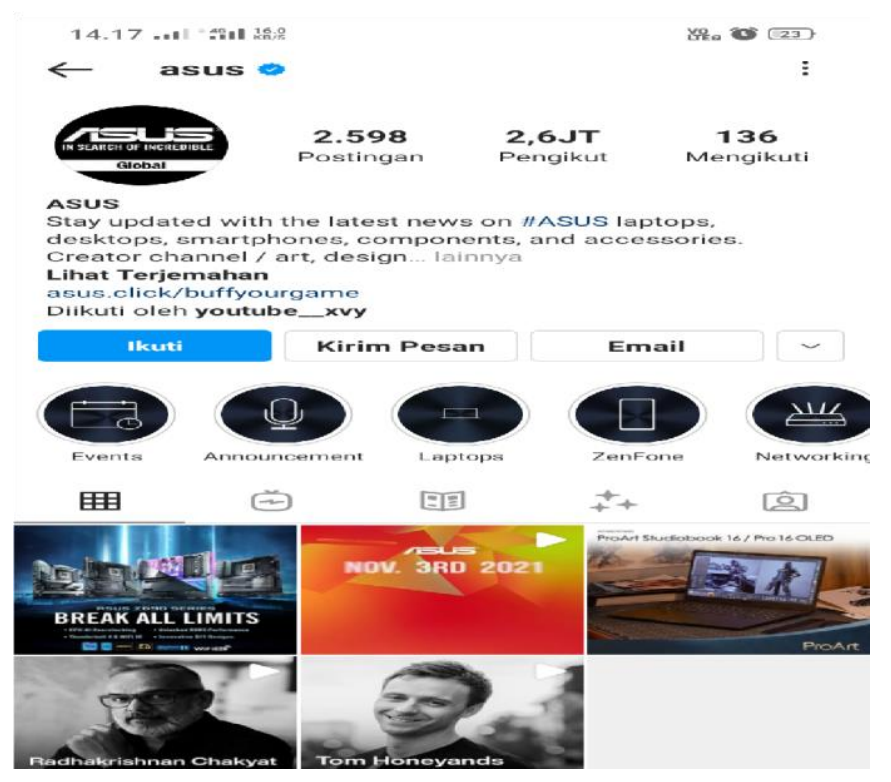

Gambar 4. Akun Akun Instragram ASUS 


\section{LENOVO}

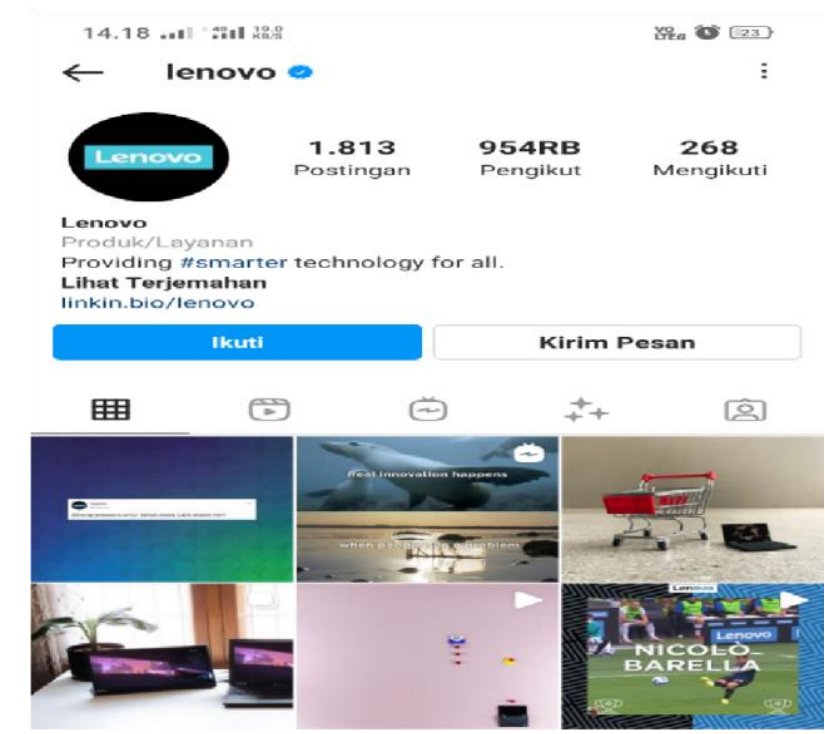

Gambar 5. Akun Akun Instragram LENOVO

Dari Kelima Akun Instragram Top 5 Vendor Laptop Di Indonesia Q1-2021, Peneliti Menemukan Nilai Dari Masing-Masing Variabel Yang Ada Untuk Menghitung Rasio Video Comments To Video Views Dari Setiap Akun. Pada Akun Instragram Terdapat 7 Variabel, Diantaranya Yaitu :

1. Likes

2. Followers

3. Following

4. Video Likes

5. Video Comments

6. Video Share

7. Video Views

Dari Ketujuh Variabel Tersebut Peneliti Hanya Fokus Untuk Menemukan Hasil Dari 2 Variabel, Yaitu :

1. Video Comments

2. Video Views

Dari Kedua Variabel Tersebut Kemudian Dianalisa Sehingga Menemukan Nilai Rata-Rata Dari Variabel Video Comments Dan Variabel Video Views. Untuk Menghitung Nilai RataRata Dari Variabel Video Comments Dan Variabel Video Views Yaitu Dengan Cara Mengambil Minimal 10 Postingan Kemudian Di Hitung Sehingga Menemukan Nilai RataRata Dari Masing-Masing Variabel. Berikut Merupakan Tabel Nilai Rata-Rata Dari MasingMasing Vendor Laptop Di Indonesia, Yaitu : 
Tabel 1. Analisa Nilai Rata-Rata Nilai Variabel Video Comments Dan Video Views Akun Instragram DELL

\begin{tabular}{|c|c|c|}
\hline NO & $\begin{array}{l}\text { IMAGE } \\
\text { COMENT }\end{array}$ & $\begin{array}{l}\text { VIDIO } \\
\text { COMENT }\end{array}$ \\
\hline 1 & 19 & 12 \\
\hline 2 & 37 & 31 \\
\hline 3 & 57 & 51 \\
\hline 4 & 36 & 44 \\
\hline 5 & 127 & 113 \\
\hline 6 & 120 & 121 \\
\hline 7 & 178 & 48 \\
\hline 8 & 54 & 151 \\
\hline 9 & 132 & 41 \\
\hline 10 & 120 & 81 \\
\hline TOTAL & 88 & 69,3 \\
\hline
\end{tabular}

Sumber : Pengolah Data Excel

Tabel 2. Analisa Nilai Rata-Rata Nilai Variabel Video Comments Dan Video Views Akun Instragram HP

\begin{tabular}{|r|l|l|}
\hline \multicolumn{1}{|l|}{ NO } & \multicolumn{2}{|l|}{$\begin{array}{l}\text { IMAGE } \\
\text { COMENT }\end{array}$} \\
\hline 1 & 13 & 25 \\
\hline 2 & 28 & 19 \\
\hline 3 & 11 & 179 \\
\hline 4 & 17 & 67 \\
\hline 5 & 145 & 44 \\
\hline 6 & 79 & 29 \\
\hline 7 & 32 & 16 \\
\hline 8 & 145 & 87 \\
\hline 9 & 79 & 79 \\
\hline 10 & 32 & 102 \\
\hline TOTAL & 58,1 & 64,7 \\
\hline Sumb
\end{tabular}

Sumber : Pengolah Data Excel 
Tabel 3. Analisa Nilai Rata-Rata Nilai Variabel Video Comments Dan Video Views Akun Instragram APPLE

\begin{tabular}{|r|r|r|}
\hline \multicolumn{1}{|l|}{ NO } & \multicolumn{2}{|l|}{$\begin{array}{l}\text { IMAGE } \\
\text { COMENT }\end{array}$} \\
\hline 1 & 404 & 1791 \\
\hline 2 & 889 & 1584 \\
\hline 3 & 402 & 535 \\
\hline 4 & 282 & 530 \\
\hline 5 & 449 & 703 \\
\hline 6 & 471 & 577 \\
\hline 7 & 974 & 382 \\
\hline 8 & 713 & 663 \\
\hline 9 & 993 & 5050 \\
\hline 10 & 487 & 1248 \\
\hline TOTAL & 606,4 & 1306,3 \\
\hline
\end{tabular}

Sumber : Pengolah Data Excel

Tabel 4. Analisa Nilai Rata-Rata Nilai Variabel Video Comments Dan Video Views Akun INSTRAGRAN ASUS

\begin{tabular}{|r|l|l|}
\hline \multicolumn{1}{|l|}{ NO } & $\begin{array}{l}\text { IMAGE } \\
\text { COMENT }\end{array}$ & $\begin{array}{l}\text { VIDIO } \\
\text { COMENT }\end{array}$ \\
\hline 1 & 7 & 15 \\
\hline 2 & 21 & 6 \\
\hline 3 & 10 & 6 \\
\hline 4 & 30 & 27 \\
\hline 5 & 32 & 20 \\
\hline 6 & 10 & 22 \\
\hline 7 & 42 & 35 \\
\hline 8 & 17 & 34 \\
\hline 9 & 26 & 30 \\
\hline 10 & 84 & 45 \\
\hline TOTAL & 27,9 & 24 \\
\hline
\end{tabular}

Sumber : Pengolah Data Excel 
Tabel 5. Analisa Rata-Rata Nilai Variabel Video Comments Dan Video Views Akun INSTRAGRAM LENOVO

\begin{tabular}{|r|r|l|}
\hline \multicolumn{1}{|l|}{ NO } & \multicolumn{2}{|l|}{$\begin{array}{l}\text { IMAGE } \\
\text { COMENT }\end{array}$} \\
\hline 1 & 35 & 7 \\
\hline 2 & 22 & 66 \\
\hline 3 & 77 & 13 \\
\hline 4 & 216 & 20 \\
\hline 5 & 59 & 12 \\
\hline 6 & 45 & 12 \\
\hline 7 & 49 & 29 \\
\hline 8 & 51 & 2 \\
\hline 9 & 29 & 52 \\
\hline 10 & 49 & 46 \\
\hline TOTAL & 63,2 & 25,9 \\
\hline
\end{tabular}

Sumber : Pengolah Data Excel 
Setelah Menghitung Nilai Rata-Rata Tersebut, Maka Akan Menemukan Hasil Akhir Nilai Rata-Rata Dari Variabel Video Comments Dan

Tabel 6. Nilai Variabel Pada Akun INSTRAGRAM 5 Vendor CLAPTOP Di Indonesia Q12021

\begin{tabular}{|l|r|r|r|r|r|}
\hline VARIABEL & DELL & HP & APPLLE & ASUS & \multicolumn{2}{l|}{\begin{tabular}{l} 
LENOV \\
\hline IMAGE
\end{tabular}} \\
$\begin{array}{l}\text { COMENT } \\
\text { VIDIO }\end{array}$ & 68 & 58,1 & 606,4 & 27,9 & 63,2 \\
COMENT & & 64,7 & 1306,3 & 24 & 25,9 \\
\hline
\end{tabular}

Sumber : Pengolah Data Excel

Tabel 7. Hasil Perhitungan Rasio Akun INSTRAGRAM

\begin{tabular}{|r|l|r|l|l|r|c|}
\hline $\begin{array}{l}\text { N } \\
\text { O }\end{array}$ & RASIO & DELL & HP & APPLE & ASUS & LENOVO \\
\hline & Image Comments To Video & 1,2698412 & 0,897991 & 0,464212 & & 2,440154 \\
1 & Comments Ratio & 7 & & & 1,1625 & \\
\hline & CHRAKTERISTIK & TINGGI & RENDAH & RENDAH & TINGGI & TINGGI \\
\hline
\end{tabular}

Sumber : Pengolah Data Excel

Video Comments To Video Views Ratio Memiliki Karakteristik Yang Tinggi, Artinya

Semakin Tinggi Nilai Yang Dihasilkan Maka Pada Akun INSTRAGRAM Terdapat 17 Rasio Yang Relevan Digunakan Untuk Mengukur Kredibilitas Pada Masing-Masing Akun. Namun Pada Penelitian Kali Ini Hanya Berfokus

Untuk Menghitung Video Comments To Video Views Ratio. Untuk Menghitung Kredibilitas Dari Masing-Masing Akun INSTRAGRAM Setiap Vendor LAPTOP, Peneliti Menghitung Dengan Cara : Variabel 1 Akan Dibagi Dengan Variabel 2, Sehingga Ditemukan Hasil Analisisa Dari Rasio Tersebut.

Semakin Baik Kredibilitas Dari Performa Akun Tersebut. Untuk Memberikan Peringkat Pada Masing-Masing Vendor LAPTOP, Peneliti Memberikan Angka 5 Kepada Vendor Yang Mendapatkan Nilai Tertinggi Dan Angka 1 Untuk Vendor Smartphone Yang Mendapatkan Nilai Terendah. Berikut Merupakan Tabel Urutan Nilai Yang Dihasilkan Oleh Masing-Masing Vendor LAPTOP.

Tabel 8. Nilai Rasio Akun INSTRAGRAM Top 5 Vendor LAPTOP Di Indonesia Q1-2021

\begin{tabular}{|r|r|r|r|rr|}
\hline DELL & HP & & APPLLE & ASUS & LENOVO \\
\hline 3 & 5 & 4 & 2 & & 1 \\
\hline
\end{tabular}

Sumber : Pengolah Data Excel 
Dari Tabel Nilai Rasio Akun INSTRAGRAM Top 5 Vendor LAPTOP Di Indonesia Q1-2021

Dapat Simpulkan Bahwa DELL Indonesia Mendapatkan Nilai Tertinggi Untuk Rasio Video Comments To Video Views. Sedangkan Akun INTRAGRAM APPLE Mendapatkan Nilai Terendah Untuk Rasio Ini. Jadi, Pada Penelitian Ini LENOVO Memiliki Kredibilitas Performa Yang Lebih Baik Dibandingkan Dengan Vendor LAPTOP Yang Lainnya.

\section{KESIMPULAN}

Tujuan Dari Penelitian Ini Adalah Mengetahui Kredibilitas Performa Dari Akun INSTRAGRAM Top 5 Vendor LAPTOP Di Indonesia Menggunakan Video Comments To Video Views Ratio. Top 5 Vendor LAPTOP Tersebut Diantaranya :DELL, HP, APPLE, ASUS, Dan LENOVO. Dari Kelima Vendor LAPTOP Tersebut Dapat Disimpulkan Bahwa :

1. Peringkat Pertama Diraih Oleh Vendor LENOVO Dengan Nilai Tertinggi Yaitu 2,440154

2. Peringkat Kedua Diraih Oleh Vendor DELL Dengan Nilai 1,26984127

3. Peringkat Ketiga Diraih Oleh Vendor ASUS Dengan Nilai 1,1625

4. Peringkat Keempat Diraih Oleh Vendor HP Dengan Nilai 0,897991

Peringkat Kelima Diraih Oleh Vendor APPLE Dengan Nilai Terendah Yaitu 0,464212 


\section{DAFTAR PUSTAKA}

Adawiyah, Dwi Putri Robiatul. 2020. "Pengaruh Penggunaan Aplikasi TikTok Terhadap Kepercayaan Diri Remaja Di Kabupaten Sampang.” Jurnal Komunikasi 14 (2): 135-48. https://doi.org/10.21107/ilkom.v14i2.7504.

Batam, Universitas Internasional. 2020. "ANALISIS FENOMENA SOSIAL MEDIA DAN KAUM MILENIAL : STUDI KASUS TIKTOK” 1: 565-72.

Ishihara, Yemikaori Yumna Ulya, and Roswita Oktavianti. 2021. "Personal Branding Influencer Di Media Sosial TikTok.” Koneksi 5 (1): 76-82. https://doi.org/10.24912/KN.V5I1.10162.

Maryam, Siti, Isrok'atun Isrok'atun, and Ani Nur Aeni. 2016. "PENDEKATAN EKSPLORATIF UNTUK MENINGKATKAN KEMAMPUAN REPRESENTASI MATEMATIS DAN KEPERCAYAAN DIRI SISWA.” Jurnal Pena Ilmiah 1 (1): 55160. https://doi.org/10.23819/PI.V1I1.2984.

P3M STMIK Widya Cipta Dharma. n.d. "SEBATIK VOL 25 NO 1 - Google Books.” 2021. Accessed October 15, 2021. https://www.google.co.id/books/edition/SEBATIK_VOL_25_NO_1/UzsyEAAAQBAJ? $\mathrm{hl}=\mathrm{id} \& \mathrm{gbpv}=1 \& \mathrm{dq}=$ tiktok+adalah \&pg=PA9\&printsec=frontcover.

Permana, I Putu Hendika, and Ni Putu Suci Meinarni. 2021. "Ratio Analysis on Tiktok (Social Media) for Qualitative Research Using Explorative Methods.” Jurnal Ekonomi \& Bisnis JAGADITHA 8 (1): 30-38. https://doi.org/10.22225/JJ.8.1.2944.30-38.

PRIANBODO, BAGUS. 2018. "PENGARUH 'TIKTOK' TERHADAP KREATIVITAS REMAJA SURABAYA,” December.

Purnamasari, Nurjihan Pricillia, and Ririn Puspita Tutiasri. 2021. “Analisis Resepsi Remaja Perempuan Terhadap Gaya Hidup Berbelanja Fashion Melalui Tayangan Video 'Belanja Gak Aturan' Dalam Akun Tiktok @handmadeshoesby.” Jurnal Representamen 7 (01). https://doi.org/10.30996/REPRESENTAMEN.V7I01.5129.

Putri, Shani Dwi, and Suzy Azeharie. 2021. "Strategi Pengelolaan Komunikasi Dalam Membentuk Personal Branding Di Media Sosial Tiktok.” Koneksi 5 (2): 280-88. https://doi.org/10.24912/KN.V5I2.10300.

Rankuti, Freddy. 2015. “Buku Riset Pemasaran.” 2015.

“Top 5 Vendor Smartphone Di Indonesia Q1-2021 - Selular.ID.” n.d. Accessed October 15, 2021. https://selular.id/2021/05/top-5-vendor-smartphone-di-indonesia-q1-2021/.

Wijaya, Mukhammad Handy dwi, and Musta'in Mashud. 2020. "Konsumsi Media Sosial Bagi Kalangan Pelajar: Studi Pada Hyperrealitas Tik Tok.” Al-Mada: Jurnal Agama, Sosial, Dan Budaya 3 (2): 170-91. https://doi.org/10.31538/ALMADA.V3I2.734. 